\title{
Time Course of Recovery is Similar for the Back Squat, Bench Press, and Deadlift in Well-Trained Males
}

\begin{tabular}{|c|c|}
\hline Journal: & Applied Physiology, Nutrition, and Metabolism \\
\hline Manuscript ID & apnm-2019-0004.R1 \\
\hline Manuscript Type: & Article \\
\hline $\begin{array}{r}\text { Date Submitted by the } \\
\text { Author: }\end{array}$ & 02-Feb-2019 \\
\hline Complete List of Authors: & $\begin{array}{l}\text { Belcher, Daniel; Florida Atlantic University, Exercise Science and Health } \\
\text { Promotion, Muscle Physiology Laboratory } \\
\text { Sousa, Colby; Florida Atlantic University, Exercise Science and Health } \\
\text { Promotion, Muscle Physiology Laboratory } \\
\text { Carzoli, Joseph; Florida Atlantic University, Exercise Science and Health } \\
\text { Promotion, Muscle Physiology Laboratory } \\
\text { Johnson, Trevor; Florida Atlantic University, Exercise Science and Health } \\
\text { Promotion, Muscle Physiology Laboratory } \\
\text { Helms, Eric; Auckland University of Technology, Sports Performance } \\
\text { Research Institute } \\
\text { Visavadiya, Nishant; Florida Atlantic University, Exercise Science and } \\
\text { Health Promotion, Muscle Physiology Laboratory } \\
\text { Zoeller, Robert F.; Florida Atlantic University, Exercise Science and } \\
\text { Health Promotion, Muscle Physiology Laboratory } \\
\text { Whitehurst, Michael; Florida Atlantic University, Exercise Science and } \\
\text { Health Promotion, Muscle Physiology Laboratory } \\
\text { Zourdos, Michael; Florida Atlantic University, Exercise Science and } \\
\text { Health Promotion, Muscle Physiology Laboratory }\end{array}$ \\
\hline Keyword: & $\begin{array}{l}\text { fatigue }<\text { exercise, muscle damage }<\text { muscle, strength training }< \\
\text { exercise, performance }<\text { performance, resistance exercise }<\text { exercise, } \\
\text { Programming }\end{array}$ \\
\hline $\begin{array}{l}\text { Is the invited manuscript for } \\
\text { consideration in a Special } \\
\text { Issue? : }\end{array}$ & Not applicable (regular submission) \\
\hline
\end{tabular}

\section{SCHOLARONE \\ Manuscripts}




\title{
Time Course of Recovery is Similar for the Back Squat, Bench Press, and Deadlift in Well-Trained Males
}

\author{
Daniel J. Belcher ${ }^{1}$ \\ Colby A. Sousa ${ }^{1}$ \\ Joseph P. Carzoli ${ }^{1}$ \\ Trevor K. Johnson ${ }^{1}$ \\ Eric R. Helms ${ }^{2}$ \\ Nishant P. Visavadiya ${ }^{1}$ \\ Robert F. Zoeller ${ }^{1}$ \\ Michael Whitehurst ${ }^{1}$ \\ Michael C. Zourdos ${ }^{1}$
}

Running Head: Squat, Bench, Deadlift Time Course Recovery

${ }^{1}$ Florida Atlantic University, Department of Exercise Science and Health Promotion, Muscle Physiology Laboratory, Boca Raton, FL, USA.

${ }^{2}$ Sports Performance Research Institute New Zealand (SPRINZ)

AUT University, Auckland, New Zealand

Corresponding Author

Michael C. Zourdos, Ph.D., CSCS

Associate Professor

Department of Exercise Science and Health Promotion

777 Glades Rd.

Florida Atlantic University

Boca Raton, FL. 33431

Office: Field House 11A, Room $126 \mathrm{~A}$

Phone: 561-297-1317, Fax: 561-297-2839

Email: mzourdos@fau.edu 


\section{Abstract}

This study examined the time course of recovery following resistance exercise sessions in the back squat, bench press, and deadlift. Twelve well-trained males (age: $24.5 \pm 3.8 \mathrm{yrs}$, body mass: $84.01 \pm 15.44 \mathrm{~kg}$, training age: $7.1 \pm 4.2 \mathrm{yrs})$ performed 4 sets to failure at $80 \%$ of a one-repetition maximum (1RM) on the squat, bench press, and deadlift in successive weeks. The bench press was always performed in week- 2 with the squat and deadlift order counterbalanced between weeks 1 and 3. Indirect muscle damage and performance fatigue was assessed immediately prior to, post-exercise, and $24,48,72$, and $96 \mathrm{hrs}$ post-exercise. Outcome measures included: limb swelling, joint range of motion, delayed onset muscle soreness, average concentric velocity (ACV) at $70 \%$ of $1 \mathrm{RM}$, creatine kinase, lactate dehydrogenase, and cell-free DNA (cfDNA). Most measures demonstrated a main time effect $(\mathrm{p}<0.05)$ within conditions, however, no between condition $(\mathrm{p}>0.05)$ differences existed. ACV decreased in the squat condition for up to 72 hours ( $\mathrm{p}=0.02,-8.61 \%)$ and in the bench press $(\mathrm{p}<0.01,-26.69 \%)$ immediately post-exercise, but did not decline during the deadlift condition $(\mathrm{p}>0.05)$. There was a main time effect for increased cfDNA in the squat $(\mathrm{p}<0.01)$ and bench press $(\mathrm{p}<0.05)$, but not the deadlift $(\mathrm{p}=0.153)$. Further, immediately post-exercise increases in cfDNA were directly related $(\mathrm{p}<0.05)$ to changes in ACV in all three conditions. These results suggest that the deadlift does not result in greater muscle damage and recovery time than the squat and bench press following volume-type training in well-trained men. Further, acute changes in cfDNA may predict performance during the recovery period.

Key words: Fatigue, Muscle Damage, Strength Training, Performance, Resistance Exercise, Programming 


\section{Introduction}

Resistance training may result in both significant muscle damage and fatigue in untrained (Newham et al. 1983; Nosaka and Newton 2002; Howatson et al. 2007) and trained individuals (Raeder et al. 2016; Barnes et al. 2017; Ferreira et al. 2017). Consequently, the magnitude and duration of the subsequent recovery then regulates both training volume and frequency (Bird et al. 2005). Recently, meta-analyses have demonstrated that an exercise or muscle group-specific training frequency of 2-3 times per week produces greater strength and hypertrophy adaptations compared to a once per week frequency (Schoenfeld et al. 2016; Grgic et al. 2018). Therefore, to make better recommendations regarding both between session rest times and recoverable single session volumes that fulfill the 2-3 time per week frequency guidelines, it is necessary to assess the time course of muscle damage and recovery in response to training.

Importantly, the magnitude of muscle damage may vary between different exercises (Soares et al. 2015). Specifically, the back squat, bench press, and deadlift are commonly used as primary training exercises by athletes (Coutts et al. 2007; International Powerlifting Federation 2015; Pritchard et al. 2016) and are frequently used in research with recreational lifters (Raeder et al. 2016; Barnes et al. 2017; Ferreira et al. 2017). Recently, Ferreira et al. (2017) observed that it took up to 96 hours for both maximal work capacity to recover and delayed onset muscle soreness (DOMS) to subside following eight sets of bench press to failure in trained lifters (Ferreira et al. 2017). In addition, Moran-Navarro (2017) demonstrated that three sets to failure at $75 \%$ of one-repetition maximum (1RM) on the back squat hindered lifting velocity and increased circulating creatine kinase (CK) for up to 72 hours (Morán-Navarro et al. 2017). These recent findings suggest that between 72 and 96 hours of recovery should be allotted between sessions if training to failure at a moderate intensity. 
Regarding the deadlift, Barnes et al. (2017) found no significant difference in the magnitude of acute fatigue between eight sets of two repetitions at $95 \%$ of $1 \mathrm{RM}$ on the squat and deadlift (Barnes et al. 2017). However, Barnes and colleagues did not assess muscle damage in the days following exercise, nor was the performed training session intended to induce significant amounts of muscle damage. Further, to our knowledge, no study has examined the time course of muscle damage and fatigue in response to a truly damaging exercise bout for the deadlift. However, despite the lack of data related to deadlift-induced temporal fatigue, recent literature has noted that in practice, this lift has been intentionally removed from training programs (Coutts et al. 2007; Pritchard et al. 2016) due to anecdotal notions that it accrues more damage and fatigue than the squat and bench press (Swinton et al. 2009; Pritchard et al. 2016). However, this practice may be unwarranted as muscle damage is largely driven by eccentric contractions (Newham et al. 1983), and the squat (Miletello et al. 2009) and bench press (Madsen and McLaughlin 1984) have greater eccentric durations than the deadlift. Further, there is relatively low muscle activity during the eccentric portion of the deadlift (Escamilla et al. 2002), thus a smaller magnitude of muscle damage should be expected following the deadlift versus the squat and bench press if volume is equated. However, the training protocols used across previous studies have varied, which makes it challenging to truly compare the time course of fatigue between exercises based upon existing evidence. The existing research related to temporal fatigue of the squat and bench press has used moderate intensities, $75 \%$ of $1 \mathrm{RM}$ (Morán-Navarro et al. 2017) and 70\% of a 10RM (Ferreira et al. 2017), which results in a greater amount of repetitions performed than when training for strength adaptations with $\geq 80 \%$ of $1 \mathrm{RM}$. To our knowledge, there is no study to date examining the time course of recovery among the squat, bench press, and deadlift when $\geq 80 \%$ of $1 \mathrm{RM}$ is used. This data is necessary to further 
understand the distribution of training volume and frequency across the various exercises when training for strength at higher intensities is the goal.

Therefore, the purpose of this study was to examine the time course of indirect muscle damage markers (i.e. creatine kinase, lactate dehydrogenase, and cell-free DNA) and performance fatigue in trained males performing four sets to volitional failure with $80 \%$ of $1 \mathrm{RM}$ on the squat, bench press, and deadlift during separate sessions in well-trained males. It was hypothesized that squat and bench press exercise would result in a similar magnitude of muscle damage and performance fatigue at all time points and that this magnitude would be greater than the deadlift due to the greater eccentric durations associated with the squat and bench press.

\section{Materials and methods}

\section{Subjects}

Participants included twelve well-trained men and subject characteristics are displayed in Table 1. For inclusion, all subjects must have performed the squat, bench press, and deadlift exercise an average of at least once per week for at least two consecutive years and total number of years training, i.e. training age (TA), was determined via a physical activity questionnaire (Zourdos et al. 2016). Further, all subjects were required to be able to perform a $1 R M$ test $\geq 1.5$ times body mass (BM) on the squat, $\geq 1$-time body mass on the bench press, and $\geq 1.5$ times body mass on the deadlift. Subjects who had any contraindications to exercise as determined via the Health History Questionnaire, were excluded from participation. All subjects were required to refrain from exercise for 48 hours prior to day one of the study. Additionally, subjects were instructed to maintain their normal general nutrition intake and nutritional supplement routine (i.e. caffeine and other stimulants) and to refrain from any additional exercise, recovery-specific 
over-the-counter medications (i.e. ibuprofen), or recovery modalities for the duration of the 3.5week protocol. Finally, the University's Institutional Review Board approved this study before its commencement and all subjects provided written informed consent prior to participation.

[Table 1 about here]

\section{Experimental design}

The aim of this study was to examine and compare the time courses of muscle damage and performance fatigue in response to acute exercise bouts of the squat, bench press, and deadlift. Subjects reported to the laboratory for 17 total sessions over a 3.5-week period. On day one of week one, subjects completed preliminary paperwork (health history and physical activity questionnaires) and had anthropometrics assessed. Next, subjects completed a five-minute standardized dynamic warm-up followed by validated 1RM testing for the squat, bench press, and deadlift on the same day (Zourdos et al. 2016). Then, 48 hours following 1RM testing, subjects performed a light exercise session for each lift ( 3 sets of 5 repetitions at $70 \% 1 \mathrm{RM}$ ). Five minutes of rest were allotted between the 1RM tests for each exercise and between sets during the light exercise session. On day one of week two, 72 hours after the light exercise session, all subjects performed four sets to volitional failure at $80 \%$ of $1 \mathrm{RM}$ on one of the three exercises. Additionally, immediately prior to and following the fatiguing exercise bout, along with 24, 48, 72, and 96 hours after, performance fatigue and indirect markers of muscle damage were assessed. The indirect markers consisted of the following: elbow and knee joint ROM, thigh and upper arm swelling, quadriceps, hamstring, and chest delayed onset muscle soreness (DOMS), as well as serum creatine kinase (CK), lactate dehydrogenase (LDH), and cell-free 
DNA (cfDNA). Finally, performance fatigue was measured by changes in average concentric velocity (ACV) during two, single repetitions with $70 \%$ of the subject's bench press, squat, and deadlift 1RM. ACV was measured, immediately prior to and following the fatiguing exercise bout, as well as 24, 48, 72, and 96 hours after the performance of the damage inducing protocol.

Following the assessments of damage and fatigue markers at 96 hours post-exercise, subjects performed a light exercise session on the two exercises which were not used in that week's damaging bout to avoid detraining on those exercises. Then, subjects had 72 hours of rest before returning to the laboratory for week three. Weeks three and four served exactly as week two except the damaging bout was performed with a different exercise. The order in which the squat and deadlift were completed were counterbalanced across subjects and separated by the bench press week (i.e. the bench press was always performed in week 2) to prevent the possibility of two lower body dominate damaging exercises from being performed in successive weeks. A detailed timeline of study procedures can be seen in Table 2.

[Table 2 about here]

\section{Exercise procedures}

\section{One-repetition maximum (1RM) testing}

All 1RM testing was conducted following previously validated procedures (Zourdos et al. 2016). Squat, bench press, and deadlift testing were completed on the same day in that order to the standard of the International Powerlifting Federation (International Powerlifting Federation 2015), and only the conventional deadlift variation was permitted. Finally, Eleiko barbells and lifting discs (Chicago, Illinois, USA) that have been calibrated to the nearest $0.25 \mathrm{~kg}$ were used 
to uphold the accuracy of load lifted. Traditional ergogenic equipment (belt, squat shoes, and wrist wraps) were permitted if regularly used by the subject prior to study participation. Further, if subjects used any of these pieces of equipment during 1RM testing then they were required to utilize this equipment in all subsequent sessions in the study. However, lifting straps were not permitted on the deadlift.

\section{Damaging exercise bouts}

Damaging exercise bouts (DEB) for the squat, bench press, and deadlift followed the same protocol. Each bout began with a five-minute dynamic warmup, followed by a specific warmup for that week's exercise wherein the subjects performed five repetitions with $20 \%$ of their $1 \mathrm{RM}$ followed by three repetitions at 50\% of 1RM. Subjects then performed two, single repetitions with $70 \%$ of $1 \mathrm{RM}$ to assess performance fatigue with a five-minute mandated rest period between repetitions. Next, following a five-minute rest period, the DEB was performed consisting of four sets to volitional failure at $80 \%$ of $1 \mathrm{RM}$, with five-minutes of rest between sets. Failure was classified as a subject actually failing on a repetition or the subject and investigator agreeing that performing an additional repetition would not be possible or would risk injury. The total number of repetitions completed for each set was recorded and repetitions were only deemed valid if they met the standards set forth by the International Powerlifting Federation (International Powerlifting Federation 2015). For the deadlift, subjects were required to keep their hands gripped on the bar throughout each set, however repositioning of the feet between repetitions was permitted. Subjects were instructed to use their normal deadlift grip and all subjects chose to see an alternate (over/under) grip. 


\section{Light exercise session}

A light exercise session was included for the squat, bench press, and deadlift 48 hours post-1RM testing, and 96 hours post-DEB each week to avoid detraining (Rønnestad et al. 2011). The light exercise bout consisting of three sets of five repetitions at $70 \%$ of $1 \mathrm{RM}$ with five minutes of rest between sets and exercises.

\section{Measurements}

\section{Anthropometric assessments}

Total BM (kg) was measured by a calibrated digital scale (Mettler-Toledo, Columbus, Ohio, USA.) and body fat percentage (BF\%) was estimated using the average sum of three skinfold thickness measurements acquired at three separate sites (abdomen, anterior thigh, and chest). The Jackson and Pollock equation was used to calculate BF\% (Jackson and Pollock 1978) and all anthropometric measurements were assessed by the same investigator.

\section{Swelling}

Limb swelling $(\mathrm{cm})$ was measured at a perpendicular angle to the limb at the midpoint of the thigh between the anterior crest of the greater trochanter and the lateral epicondyle of the femur for the squat and deadlift weeks and at the midpoint of the upper arm between the lateral acromion process and the olecranon process during bench press weeks. All measurements were made with the same tape measure on the subject's nondominant limb by the same investigator and landmark sites were marked with semi-permanent pen. Swelling measurements were assessed three consecutive times with a 30 -second interval between measurements and the mean score was recorded for analysis. 


\section{Range of motion}

Joint ROM was assessed through goniometry and determined by the difference in the tested starting and ending joint angle in the subjects nondominant limb to determine flexibility in specific muscle groups (Willy et al. 2001; Bradbury-Squires et al. 2015). Assessments of ROM occurred for the hamstrings and quadriceps at the knee joint and for the triceps at the elbow joint, and all reference points were marked by semi-permanent pen for retest reliability. Goniometer reference points for the knee included, the lateral femoral epicondyle, the articulate interline of the knee, and the lateral malleolus (Willy et al. 2001). Hamstring ROM was assessed at the knee with the subject laying in the supine position with the subject's hip placed in $90^{\circ}$ of hip flexion, and the lower leg passively hanging down, and the degree of the knee was recorded. The subject then actively extended the knee to the point of stretch induced pain, at which time the ending knee angle measurement was taken (Willy et al. 2001). Quadriceps ROM began with the subject in a kneeling lunge position with the tibia of the dominant limb perpendicular to the floor and the knee and hip at a $90^{\circ}$ angle (Bradbury-Squires et al. 2015). The angle of the non-dominant knee was then recorded as the starting angle. Next, while the subject maintained an upright torso, the investigator passively flexed the nondominant knee until the point that the subject experienced stretch induced pain in the quadriceps (Bradbury-Squires et al. 2015). This point was then recorded as the final angle for quadriceps ROM. For assessments of elbow ROM, goniometer reference points included the proximal apex of deltoid, axis of rotation of the elbow, styloid process, and dorsal tubercle of the radius (Zourdos et al. 2015). The starting angle was taken at the joint angle of the elbow while fully flexed with the subject's palm facing their shoulder; and the final angle was assessed by having the subject fully extending their arm downward 
(Zainuddin et al. 2005). All ROMs were conducted in triplicate by the same investigator 30seconds apart and averaged for analysis.

\section{Delayed onset muscle soreness}

Pressure-pain threshold was used to assess DOMS and is defined as the minimal amount of pressure needed to induce pain (Fischer 1987; Rocha et al. 2012). Subjects were tested in a relaxed standing position for quadriceps assessments and laying in the prone position for hamstrings assessments. The probe of an algometer (Wagner Instruments; Greenwich, CT, USA) was placed into the midline of the vastus lateralis at the midpoint between the iliac crest and the superior border of the patella (Rocha et al. 2012) and into the midline of the biceps femoris at the distal $40 \%$ point between the articulate interline of the knee and the head of the femur (Pearcey et al. 2015), for the squat and deadlift weeks. For the bench press week, algometer palpations occurred on the pectoralis major just medial to the anterior point of the axillary line (Rønnestad et al. 2011). For all palpations, force began at $0 \mathrm{kPa} / \mathrm{s}$ and was gradually increased at a constant rate of 50 to $60 \mathrm{kPa} / \mathrm{s}$ until the subject indicated the presence of pain. All pressure-pain threshold assessments were tested on each subject's nondominant side and subjects were instructed to say "now" the instant pain was felt rather than pressure and the pressure at which pain was induced was recorded. Assessments were completed three consecutive times with 30 -second intervals between measurements.

Scores were recorded in kilograms per centimeter squared and converted to kilopascals (1 $\mathrm{kg} / \mathrm{cm}^{2}=98.1 \mathrm{kPa}$ ) and the mean score of the three trials was used for analysis. To maintain reliability between assessments, the same investigator conducted all measurements throughout the protocol and each DOMS assessment site was marked by semi-permanent pen to maintain 
homogeny during repeated assessments. The outlined protocol for DOMS assessment was in accordance with previously validated measures (Fischer 1987; Rocha et al. 2012).

\section{Blood sampling and analysis}

Serum was collected through venous blood collected from the antecubital vein through sterile venipuncture techniques into serum separating tubes. Samples were set aside for 20-30 minutes to clot at room temperature and then centrifuged for 10 minutes at 2,000 x G to obtain serum. Following separation, all serum samples were aliquoted and stored at $-80^{\circ} \mathrm{C}$ until analysis. Both LDH and CK activity was measured with the Epoch ${ }^{\mathrm{TM}}$ microplate spectrophotometer (BioTek Instruments, Winooski, VT, USA) through commercially available colorimetric assay kits (Cat\# K726, Lactate Dehydrogenase Activity Colorimetric Assay Kit and Cat\# K777, Creatine Kinase Activity Colorimetric Assay Kit, BioVision, Milpitas, CA, USA) and analyzed in duplicate. Analysis of cfDNA was assessed fluorometrically through the Synergy $^{\text {TM }}$ HTX Multi-Mode microplate reader (BioTek Instruments, Winooski, VT, USA) using a fluorescent SYBR ${ }^{\text {TM }}$ Gold nucleic acid stain (Cat\# S11494, Thermo Fisher Scientific; Rockford, IL, USA) following similar procedures to a previously validated assay (Goldshtein et al. 2009). In short, $20 \mu 1$ of serum were added to 96 -well plates in duplicate followed by $80 \mu 1$ of SYBRTM $^{\text {TM }}$ Gold (diluted first at 1:1,000 in DMSO and followed by a 1:8 dilution in PBS) and fluorescents was recorded at an excitation wavelength of $485 \mathrm{~nm}$, and emission wavelength of $535 \mathrm{~nm}$. A standard curve was established in duplicate at seven concentrations ( 0 to $5,000 \mathrm{ng} / \mathrm{ml})$ through serial dilution of UltraPure ${ }^{\mathrm{TM}}$ salmon sperm DNA (Cat\#15632011, Thermo Fisher Scientific; Rockford, IL, USA). 


\section{Average concentric velocity}

Following the completion of exercise specific warm-ups, subjects performed two single repetition sets of the week's tested exercise at $70 \%$ of $1 \mathrm{RM}$ as a measure of performance fatigue at the following time points each week: on day 1 prior to and immediately following the DEB, then again at 24, 48, 72, and 96 hours post-exercise. All ACV $\left(\mathrm{m}^{-1}\right)$ were measured via the Open Barbell System Version 3 (OBS3) (Squats \& Science; NYC, New York, USA.). The OBS3 is a portable linear position transducer, which has a velocity sensor with a display unit and attaches to the barbell (just inside of the "sleeve") via a cord with a Velcro strap. The outlined procedures for obtaining daily ACV followed a similar previously validated method (MoránNavarro et al. 2017) and subjects were instructed to lift the weight as fast as possible.

\section{Statistical analyses}

A one-way repeated measures ANOVA was used to determine changes within each condition (i.e. each individual lift) from the pre-exercise time point for ROM, DOMS, CK, LDH, cfDNA, and ACV. To compare differences between exercises, percentage changes from preexercise to each time post-exercise time-point were calculated. Then, a 3 (condition) x 5 (time point) repeated measures ANOVA was used to assess the percentage change values. Percentage change values were calculated to standardize between-condition comparisons as the mean values differed due to the different measures being compared (i.e. chest soreness vs. thigh soreness). In the event of a main time effect a Tukey's post hoc test was used to detect significant mean differences within or between exercises. Correlations between the percentage changes in cfDNA and ACV within each exercise were calculated using Pearson product-moment correlation 
coefficients. All statistical analyses were performed using GraphPad Prism 7 for Windows (San Diego, CA, USA) and the levels of significance were all set at $\mathrm{p} \leq 0.05$.

\section{Results}

\section{Total volume}

For descriptive purposes, total volume load for each exercise was as follows: squat - 3908 $\pm 1076 \mathrm{~kg}$, deadlift $-4470 \pm 855.7 \mathrm{~kg}$., and bench press $-3009 \pm 701.5 \mathrm{~kg}$. A statistical comparison for these volume loads was not conducted since total displacement during each exercise was not calculated to provide a fair between-exercise comparison.

\section{Within-exercise damage response}

\section{Swelling}

There was a significant main time effect observed for thigh swelling in the deadlift $(p<0.01)$, squat $(p<0.01)$, and for arm swelling in the bench press $(p<0.01)$. For the bench press specifically, there was a significant increase in arm swelling immediately post-exercise $(\mathrm{p}<0.01$, $+2.32 \%)$ (Figure 1A).

\section{Range of motion}

A significant main time effect $(\mathrm{p}<0.01)$ noting a decrease in elbow ROM was observed in the bench press condition. Main effects for quadriceps and hamstring ROM showed a decline that were significant $(\mathrm{p}<0.035)$ and approaching $(\mathrm{p}=0.074)$ significance, respectively, in the squat condition. However, no meaningful change in hamstring $(p=0.57)$ and quadriceps $(p=0.32)$ ROM was observed following the deadlift (Figures 1C and 1D). Further, post-hoc analysis 
revealed that the only significant decrease in ROM at a specific time point was for elbow ROM immediately post-exercise in the bench press condition $(\mathrm{p}<0.05,-2.62 \%)$.

\section{Delayed onset muscle soreness}

Significant main time effects showing decreased pain-pressure threshold (i.e. increased DOMS) were observed for the chest following the bench press $(\mathrm{p}<0.01)$, and were driven by significant changes from baseline at 24 hours $(p<0.01,-25.63 \%)$ and 48 hours $(p<0.05,-19.26 \%)$ post-exercise (Figure 1E \& 1F). For squat, a main time effect was observed for both hamstring $(\mathrm{p}<0.01)$ and quadriceps $(\mathrm{p}<0.01)$ pain-pressure threshold. Post-hoc analysis revealed significantly decreased pain-pressure threshold at $24(\mathrm{p}<0.01,-26.73 \%)$ and 48 hours for the hamstring $(\mathrm{p}<0.01,-17.90 \%)$ (Figure 1E), and at $24(\mathrm{p}<0.01,-18 \%), 48(\mathrm{p}<0.01,-20.13 \%)$, and 72 hours $(\mathrm{p}<0.01,-11.91 \%)$ post-exercise in the quadriceps (Figure 1F). Finally, there was a significant main time effect for quadriceps pain-pressure threshold in the deadlift $(\mathrm{p}<0.01)$ with $24(\mathrm{p}<0.01,-16.51 \%)$ and 48 hours $(\mathrm{p}<0.01,-10.56 \%)$ post-exercise (Figure $1 \mathrm{~F})$. However, no main time effect was found for hamstring pain-pressure threshold $(p=0.214)$ in the deadlift condition (Figure 1E).

[Figure 1 about here]

\section{Lactate dehydrogenase}

Both the squat $(p=0.01)$ and bench press $(p<0.01)$ conditions produced significant main time effects showing increased LDH, while the main effect for LDH approached a significance in the deadlift condition $(\mathrm{p}=0.071)$. Post-hoc analysis revealed that immediately post-exercise, 
LDH was significantly elevated compared to baseline in the squat condition only $(p=0.01$, $+16.38 \%$ ) (Figure $2 \mathrm{~A})$. The intra-assay coefficient of variation for LDH was $6.57 \%$.

\section{Creatine kinase}

Significant time effects for CK were found for all three conditions $(p<0.01)$, with a significant increase immediately post-exercise in the squat $(p<0.01,+66.99 \%)$ and deadlift $(\mathrm{p}<0.01,+76.77 \%)$ conditions (Figure 2B). The intra-assay coefficient of variation for CK was $7.10 \%$.

\section{Cell-free DNA}

A significant main time effect was observed for cfDNA in the squat $(\mathrm{p}<0.01)$ and bench press $(p<0.05)$, while no meaningful change was observed following the deadlift $(p=0.153)$. A post-hoc analysis revealed no significant change from baseline at any time point for all three exercises (Figure 2C). The intra-assay coefficient of variation for cfDNA was $3.52 \%$

[Figure 2 about here]

\section{Average concentric velocity}

There was a time effect showing a decrease in ACV in the squat $(\mathrm{p}<0.01)$ and bench press $(\mathrm{p}<0.01)$ conditions, however, no change in ACV was observed in the deadlift condition $(\mathrm{p}=0.216)$. For squat, post-hoc analysis revealed a significant decline in ACV compared to baseline immediately $(\mathrm{p}<0.01,-9.85 \%), 24(\mathrm{p}<0.01,-9.13 \%), 48(\mathrm{p}<0.01,-11.39 \%)$, and 72 
hours ( $\mathrm{p}=0.02,-8.61 \%$ ) post-exercise. In the bench press there was a significant decrease in ACV only immediately post-exercise ( $<<0.01,-26.69 \%$ ) (Figure 1B).

\section{Between exercise comparisons}

There were no condition effects for any of the dependent variables ( $p>0.05)$. However, significant condition by time interaction effects were found for swelling ( $<<0.01)$, quadriceps and elbow ROM ( $\mathrm{p}=0.05)$, quadriceps and chest DOMS ( $<<0.05)$, and ACV $(\mathrm{p}<0.01)$. Specifically, a significant condition by time interaction was observed showing arm swelling in the bench press condition increased by a significantly greater percentage immediately postexercise than thigh swelling in the squat $(\mathrm{p}<0.01)$ or deadlift $(\mathrm{p}<0.01)$. Joint ROM was significantly reduced at the hamstring in the squat condition compared to the elbow in the bench press condition at 48 hours post-exercise $(\mathrm{p}<0.05)$. Significant decreases in quadriceps ROM in the deadlift were also found when compared to the squat at the immediate $(\mathrm{p}=0.05)$ and 96 hour $(\mathrm{p}<0.01)$ post-exercise time points. Additional significant losses in ROM were also observed to be great in the bench press over the squat at 96 hours post-exercise $(\mathrm{p}=0.01)$. Additionally, chest pain-pressure threshold was significantly increased in the bench press when compared to the quadriceps in the deadlift $(\mathrm{p}<0.05)$ immediately post-exercise. At 72 hours post-exercise, LDH was significantly lower $(p<0.05)$ in the bench press condition versus squat. Finally, compared to both the squat and deadlift, a significantly greater decrease in ACV immediately post-exercise was observed in the bench press $(\mathrm{p}<0.01)$. The percentage changes from baseline for each variable across all conditions and time points are displayed in Table 3.

[Table 3 about here] 


\section{Relationships between cfDNA and ACV}

Various significant and positive correlations existed between the percentage change in cfDNA and the percentage change in squat and deadlift ACV, however, no relationships existed between cfDNA and bench press ACV. All significant correlations were positive indicating that greater increases in cfDNA were associated with increases or an attenuated rate of decline in $\mathrm{ACV}$.

For squat the following relationships were observed: change in cfDNA and ACV immediately following exercise $(r=0.639, \mathrm{p}=0.019)$ (Figure $3 \mathrm{~A})$, changes in each variable at 24 hours post-exercise $(r=0.638, \mathrm{p}=0.019)$, changes in each variable at 48 hours post-exercise $(\mathrm{r}=0.605, \mathrm{p}=0.028)$, and the change in cfDNA at 48 hours and squat ACV at 72 hours postexercise $(r=0.592, p=0.033)$. Further, the following relationships approached significance between cfDNA and squat ACV: change in cfDNA from baseline to 24 hours with change in squat $\mathrm{ACV}$ at 72 hours $(\mathrm{r}=0.530, \mathrm{p}=0.062)$ and the change in each variable from baseline to 72 hours post-exercise $(\mathrm{r}=0.490, \mathrm{p}=0.089)$.

For the deadlift the percentage change in cfDNA from baseline to immediately postexercise was significantly correlated or approached a significance relationship with the change in deadlift ACV from baseline to every time point (Figure 3B). Additionally, significant associations were also observed between the percentage change in cfDNA at 24 hours and ACV at 96 hours post-exercise $(r=0.606, p=0.037)$, between cfDNA at 72 hours post-exercise and $\mathrm{ACV}$ at $72(\mathrm{r}=0.655, \mathrm{p}=0.021)$ and 96 hours post-exercise $(\mathrm{r}=0.683, \mathrm{p}=0.014)$, and between cfDNA and ACV at 96 hours post-exercise $(r=0.685, \mathrm{p}=0.014)$.

[Figure 3 about here] 


\section{Discussion}

To our current knowledge this is not only the first study to examine indirect muscle damage in the deadlift but also the first to directly compare it and fatigue across the squat, bench press, and deadlift. As expected, significant muscle damage was indicated in most indirect markers across all conditions, with the exception of cfDNA in the deadlift. There were no data which clearly demonstrated longer lasting fatigue in one condition versus the other, however, ACV decreased immediately following exercise in the squat and bench press, but not the deadlift (Figure 1B). Therefore, our hypothesis was partially supported that the bench press and squat would induce a greater magnitude of fatigue than the deadlift. Our data refutes the commonly held belief that the time course of recovery, based upon the indirect markers of muscle damage and performance fatigue measured presently, for the deadlift is longer compared to the squat and bench press.

Although there were no changes in quadriceps swelling following the squat, painpressure threshold in the hamstrings and quadriceps were significantly reduced for up to 48 and 72 (Figures $1 \mathrm{E} \& 1 \mathrm{~F}$ ) hours respectively, indicating significant DOMS. Interestingly, in the squat condition, enzymes $\mathrm{CK}$ and $\mathrm{LDH}$ both peaked immediately post-exercise and returned to baseline within 24 hours (Figures 2A \& 2B). In contrast, Moran-Navarro et al. (2017) observed that CK peaked at 24 hours post-exercise and did not return to pre-exercise levels for up to 72 hours following three sets to failure in the squat (Morán-Navarro et al. 2017). To explain the discrepancy in time course, the average squat 1RM of subjects in the present study $(159.00 \pm$ $49.25 \mathrm{~kg}$ ), was substantially greater than Moran-Navarro et al. (105.7 $\pm 35.2 \mathrm{~kg})$ suggesting that the higher training status of our subjects resulted in a more rapid recovery (Morán-Navarro et al. 2017). Further, Moran-Navarro performed both the squat and bench press during the same 
exercise session, which likely elevated circulating levels of these enzymes to a greater degree. Despite the recovery of peripheral $\mathrm{CK}$ and $\mathrm{LDH}, \mathrm{ACV}$ in the squat remained significantly decreased for 72 hours ( $\mathrm{p}=0.03,-8.61 \%$ ), yet Moran-Navarro reported squat ACV to be recovered at 48 hours (14). It is difficult to know exactly why there is a discrepancy between these studies, however, it seems clear that at least 48 hours is needed between squat sessions to failure. Further, research should continue to investigate measures of performance fatigue (i.e. $\mathrm{ACV}$ ) in addition to indirect markers of muscle damage since recovery of circulating $\mathrm{CK}$ and LDH does not seem to always coincide with performance recovery.

Following the bench press there was significant upper arm limb swelling immediately post-exercise $(\mathrm{p}<0.01,+2.32 \%)$, likely due to reactive hyperemia, as swelling recovered by 24 hours post-exercise (Figure 1A). Interestingly, decreases in chest pain-pressure thresholds (indicating significant DOMS) peaked at 24 hours and were recovered by 48 hours (Figures 1C \& 1D). Ferreira et al. (2017) reported elevated DOMS at 96 hours following eight sets to failure at $\sim 50-70 \%$ of $1 \mathrm{RM}$ in the bench press (Ferreira et al. 2017). The greater training volume and lower training status in Ferreira et al. likely explains the shorter bench press recovery time in the present study.

Furthermore, similar to the CK and LDH responses in the squat, peak concentrations in the bench press condition occurred immediately post-exercise, albeit not significantly. Comparable to Moran-Navarro et al. (2017), ACV decreased in the bench press immediately post-exercise ( $<<0.01,-26.69 \%)$, but was recovered within 24 hours (Figure 1B) (MoránNavarro et al. 2017). In contrast, Ferreira et al. (2017) have shown that 96 hours may be required for complete recovery following bench press exercise. However, as previously noted the high training volume used in Ferreira et al. likely explains the differential time courses of recovery 
(Ferreira et al. 2017). Therefore, it seems wise to limit session volume as per the present study which appears to result in a more rapid recovery. In turn, this may facilitate increased training frequency and allow for increased weekly volume despite a lower per session volume.

To our knowledge, this is the first study to examine the time course of muscle damage and fatigue in well-trained lifters in response to the deadlift exercise. We observed quadriceps pain-pressure threshold to be significantly reduced (i.e. increased DOMS) for up to 48 hours $(\mathrm{p}<0.01,-11.62 \%)$ (Figure $1 \mathrm{~F})$, however, there was no change in hamstrings DOMS at any time point (Figure 1E). Further, no significant changes occurred in the swelling and LDH response, and although CK did increase significantly immediately post-exercise $(\mathrm{p}<0.01,+78.77 \%)$, it returned to baseline within 24 hours (Figure 2B). Perhaps most importantly, there was no significant decrease $(\mathrm{p}>0.05)$ in $\mathrm{ACV}$, at any time following the four sets to failure at $80 \%$ of $1 \mathrm{RM}$ in the deadlift condition (Figure 1B) despite bench press ACV being decreased at 24 hours post-exercise and squat ACV remaining significantly diminished until 72 hours post-exercise.

Previous studies have shown cfDNA as a promising biomarker for exercise-induced muscle damage and inflammation (Velders et al. 2014; Tug et al. 2016; Andreatta et al. 2017). Presently, we observed main time-effects for serum cfDNA in the squat $(p<0.01)$ and bench press $(\mathrm{p}<0.05)$ conditions, but no change was observed in the deadlift condition $(\mathrm{p}>0.05)$. Interestingly, many direct relationships were observed between the percentage changes in postexercise cfDNA and ACV in the squat and deadlift conditions (Figure 3). In contrast, Andreatta et al. (2017) found significant inverse relationships between post-exercise cfDNA concentrations and performance markers at 24 hours post-exercise (Andreatta et al. 2017). A possible explanation for the discrepancies between these data may lay within the specific timing of the post-exercise blood collections or the variability in individual DNAse kinetics. Recently, Velders 
et al. (2014) observed that exercised-induced increases in serum cfDNA begins to degrade within seven minutes following high intensity exercise in trained rowers, likely due to tandem increases in DNAse activity (Velders et al. 2014). The aforementioned study also reported variations in cfDNA changes at seven minutes vs. immediate post-exercise time points with half of the subjects experiencing an increase and half a decrease in total serum cfDNA content. Further, Beiter et al. (2014) also demonstrated the plasma cfDNA had returned to baseline within 30mins following an exhaustive bout of aerobic exercise in well-trained male athletes (Beiter et al. 2014). Even though blood was collected immediately post-exercise in the present study, this was $\sim 10$ minutes after the completion of the damaging training (4 sets to failure) since two single repetition sets at $70 \%$ of $1 \mathrm{RM}$ were completed after the failure sets and before post-exercise blood collection. Thus, additional studies are warranted exploring the role of cfDNA and DNAse kinetics following resistance exercise.

Between-condition comparisons showed significantly greater declines in bench press ACV immediately post-exercise compared to the deadlift and significantly greater limb swelling immediately post-exercise compared to both the squat and deadlift. Interestingly, no condition $\mathrm{x}$ time interactions occurred between the squat and deadlift, yet ACV was decreased for up to 72 hours in the squat and did not decrease at any time point in the deadlift. This data is important due to the commonly held belief that deadlift training causes more fatigue than squat training (Swinton et al. 2009; Pritchard et al. 2016) and previous literature suggesting that the deadlift should be performed with a lower frequency (Coutts et al. 2007; Pritchard et al. 2016). In contrast, the present data demonstrates the opposite, showing that performance fatigue recovered more quickly in the deadlift than in the squat and other measures recovered at a similar rate. Further, Barnes et al. (2017) demonstrated similar fatigue between the squat and deadlift as they 
observed isometric strength and activation of the quadriceps to decrease to a similar degree and no significant difference in central fatigue following eight sets of two repetitions at 95\% of 1RM on each exercise in a crossover design (Barnes et al. 2017). The acute findings from Barnes et al. in addition to the present time course findings suggest that deadlift training can be safely performed with a frequency of at least twice per week in well-trained individuals.

\section{Limitations}

The current study is not without limitations. One being that the present study only used well-trained young males which decreases the ability to extrapolate these findings to other populations, since it is well-known that a more trained muscle is less susceptible to muscle damage (Zourdos et al. 2015), thus the time course of fatigue to the same relative training volume (4 sets X max repetitions X $80 \%$ of 1RM) would likely be different in a less-trained population. Further, Barnes et al. (Barnes et al. 2017) demonstrated no difference in central fatigue to acute bouts of high intensity squat and deadlift, however, no central fatigue measures were assessed presently. However, the current training status also a strength as there is a paucity of data related to fatigue responses in truly well-trained lifters. Furthermore, the present study required subjects to train to failure in an effort to ensure significant damage and fatigue, however, failure training is not a requirement to maximize hypertrophy and strength adaptations (Davies et al. 2016), and is likely suboptimal for well-trained lifters (Carroll et al. 2018). Thus, further research should be carried out to examine the time course of fatigue when leaving 2-3 repetitions in reserve. Additionally, caution should be used when interpreting the time course of $\mathrm{ACV}$ recovery at $70 \%$ of $1 \mathrm{RM}$ (such as presently) as this measure is only a proxy for recovery of 1RM strength or volume performance capability. Thus, it cannot truly be known when recovery 
fully occurred in the present study to the point where a typical exercise session could have been performed. Further, the methodology used for the limb swelling assessments (i.e. tape measurements) in the present study may have failed to detect significant changes throughout the recovery period due to its limited sensitivity; and possible differences may have been found in if a more advanced detection method (i.e. ultrasound) was utilized. Finally, the present study only included the conventional deadlift variation as opposed to the sumo deadlift style so that similar musculature was targeted between individuals, thus it cannot be known from this study what the time course of fatigue would be in response to the sumo deadlift.

\section{Conclusions}

In summary, the present study demonstrates that indirect markers of muscle damage do not necessarily reflect performance recovery as determined by ACV. Furthermore, we demonstrate for the first time that the deadlift does not require longer recovery times than the squat or bench press and may potentially take less time to recover than the other lifts. Practically, based on these results, it still seems wise to leave 48 hours at least between training sessions on a specific exercise. However, athletes and coaches are advised to take into account individual training status along with total training volume and proximity to failure when determining recovery times. Importantly, it is advisable to manage per session training volume so that recovery can occur in a reasonably time frame (i.e. 48 hours) to meet weekly frequency and volume thresholds to optimize long-term adaptations. 


\section{Acknowledgements}

The authors would like to acknowledge all the volunteers who participated in this study and all the graduate and undergraduate students who assisted in data collection.

\section{Conflict of interest statement}

MCZ and ERH would like to disclose that they are coaches and writers within the fitness industry. Otherwise, the authors have no conflict of interest to disclose between any outside institution, company, or manufacture. The results of this study are presented clearly, honestly, and without fabrication, or inappropriate data manipulation. 


\section{References}

2 Andreatta, M. V, Curty, V.M., Coutinho, J.V.S., Santos, M.Â.A., Vassallo, P.F., de Sousa, N.F., and Barauna, V.G. 2017. cfDNA as an Earlier Predictor of Exercise-Induced Performance Decrement Related to Muscle Damage. Int. J. Sports Physiol. Perform. 13(7): 953-956. doi:10.1123/ijspp.2017-0421.

Barnes, M.J., Miller, A., Reeve, D., and Stewart, R.J. 2017. Acute neuromuscular and endocrine responses to two different compound exercises. In Journal of Strength and Conditioning Research. doi:10.1519/JSC.0000000000002140.

Beiter, T., Fragasso, A., Hudemann, J., Schild, M., Steinacker, J., Mooren, F.C., and Niess, A.M. 2014. Neutrophils release extracellular DNA traps in response to exercise. J. Appl. Physiol. 117(3): 325-333. doi:10.1152/japplphysiol.00173.2014.

Bird, S.P., Tarpenning, K.M., and Marino, F.E. 2005. Designing resistance training programmes to enhance muscular fitness: A review of the acute programme variables. Sport. Med. 35(10): 841-851. doi:10.2165/00007256-200535100-00002.

Bradbury-Squires, D.J., Noftall, J.C., Sullivan, K.M., Behm, D.G., Power, K.E., and Button, D.C. 2015. Roller-massager application to the quadriceps and knee-joint range of motion and neuromuscular efficiency during a lunge. J. Athl. Train. 50(2): 133-140. doi:10.4085/1062-6050-49.5.03.

Carroll, K.M., Bernards, J.R., Bazyler, C.D., Taber, C.B., Stuart, C.A., DeWeese, B.H., Sato, K., and Stone, M.H. 2018. Divergent Performance Outcomes Following Resistance Training Using Repetition Maximums or Relative Intensity. Int. J. Sports Physiol. Perform.: 1-8. doi:10.1123/ijspp.2018-0045.

Coutts, A., Reaburn, P., Piva, T.J., and Murphy, A. 2007. Changes in selected biochemical, 
muscular strength, power, and endurance measures during deliberate overreaching and tapering in rugby league players. Int. J. Sports Med. 28(2): 116-124. doi:10.1055/s-2006924145.

Davies, T., Orr, R., Halaki, M., and Hackett, D. 2016. Effect of training leading to repetition failure on muscular strength: A systematic review and meta-analysis. doi:10.1007/s40279015-0451-3.

Escamilla, R.F., Francisco, A.C., Kayes, A. V., Speer, K.P., and Moorman, C.T. 2002. An electromyographic analysis of sumo and conventional style deadlifts. Med. Sci. Sport. Exerc. 34(1): 682-688. doi:10.1097/00005768-200204000-00019.

Ferreira, D. V., Gentil, P., Ferreira-Junior, J.B., Soares, S.R.S., Brown, L.E., and Bottaro, M. 2017. Dissociated time course between peak torque and total work recovery following bench press training in resistance trained men. Physiol. Behav. 179: 143-147. doi:10.1016/j.physbeh.2017.06.001.

Fischer, A.A. 1987. Pressure algometry over normal muscles: Standard values, validity and reproducibility of pressure threshold. Pain 30(1): 115-126. doi:10.1016/03043959(87)90089-3.

Goldshtein, H., Hausmann, M.J., and Douvdevani, A. 2009. A rapid direct fluorescent assay for cell-free DNA quantification in biological fluids. Ann. Clin. Biochem. 46(6): 488-494. doi:10.1258/acb.2009.009002.

Grgic, J., Schoenfeld, B.J., Davies, T.B., Lazinica, B., Krieger, J.W., and Pedisic, Z. 2018. Effect of resistance training frequency on gains in muscular strength: A systematic review and meta-analysis. doi:10.1007/s40279-018-0872-X.

Howatson, G., Van Someren, K., and Hortobágyi, T. 2007. Repeated bout effect after maximal 
eccentric exercise. Int J Sport. Med 28(7): 557-563. doi:10.1055/s-2007-964866.

48

49

50

51

International Powerlifting Federation. 2015. Technical Rules Book.

Jackson, A.S., and Pollock, M.L. 1978. Generalized equations for predicting body density of men. Br. J. Nutr. 40(3): 497-504. doi:10.1079/BJN19780152.

Madsen, N., and McLaughlin, T. 1984. Kinematic factors influencing performance and injury risk in the bench press exercise. Med Sci Sport. Exerc 16(4): 376-381.

Miletello, W.M., Beam, J.R., and Cooper, Z.C. 2009. A biomechanical analysis of the squat between competitive collegiate, competitive high school, and novice powerlifters. J. Strength Cond. Res. 23(5): 1611-1617. doi:10.1519/JSC.0b013e3181a3c6ef.

Morán-Navarro, R., Pérez, C.E., Mora-Rodríguez, R., de la Cruz-Sánchez, E., González-Badillo, J.J., Sánchez-Medina, L., and Pallarés, J.G. 2017. Time course of recovery following resistance training leading or not to failure. Eur. J. Appl. Physiol.: 1-13. doi:10.1007/s00421-017-3725-7.

Newham, D.J., McPhail, G., Mills, K.R., and Edwards, R.H.T. 1983. Ultrastructural changes after concentric and eccentric contractions of human muscle. J. Neurol. Sci. 61(1): 109-122. doi:10.1016/0022-510X(83)90058-8.

Nosaka, K., and Newton, M. 2002. Concentric or eccentric training effect on eccentric exerciseinduced muscle damage. Med. Sci. Sports Exerc. 34(1): 63-69. doi:10.1097/00005768200201000-00011.

Pearcey, G.E.P., Bradbury-Squires, D.J., Kawamoto, J.-E., Drinkwater, E.J., Behm, D.G., and Button, D.C. 2015. Foam rolling for delayed-onset muscle soreness and recovery of dynamic performance measures. J. Athl. Train. 50(1): 5-13. doi:10.4085/1062-605050.1 .01 . 
70 Pritchard, H.J., Tod, D.A., Barnes, M.J., Keogh, J.W., and Mcguigan, M.R. 2016. Tapering

71 practices of New Zealand's elite raw powerlifters. J. Strength Cond. Res. 30(7): 1796-1804.

72 doi:10.1519/JSC.0000000000001292.

73 Raeder, C., Wiewelhove, T., Westphal-Martinez, M.P., Fernandez-Fernandez, J., De Paula

74 Simola, R.A., Kellmann, M., Meyer, T., Pfeiffer, M., and Ferrauti, A. 2016. Neuromuscular

75 fatigue and physiological responses after five dynamic squat exercise protocols. J. Strength

76 Cond. Res. 30(4): 953-965. doi:10.1519/JSC.0000000000001181.

77 Rocha, C.S., Lanferdini, F.J., Kolberg, C., Silva, M.F., Vaz, M.A., Partata, W.A., and Zaro, M.A.

78 2012. Interferential therapy effect on mechanical pain threshold and isometric torque after delayed onset muscle soreness induction in human hamstrings. J. Sports Sci. 30(8): 733-

81 Rønnestad, B.R., Nymark, B.S., and Raastad, T. 2011. Effects of inseason strength maintenance training frequency in professional soccer players. J. Strength Cond. Res. 25(10): 2653742. doi:10.1080/02640414.2012.672025. 2660. doi:10.1519/JSC.0b013e31822dcd96.

Schoenfeld, B.J., Ogborn, D., and Krieger, J.W. 2016. Effects of resistance training frequency on

(1)
measures of muscle hypertrophy: A systematic review and meta-analysis. Sport. Med. 46(11): 1689-1697. doi:10.1007/s40279-016-0543-8.

Soares, S., Ferreira-Junior, J.B., Pereira, M.C., Cleto, V.A., Castanheira, R.P., Cadore, E.L.,

88
Brown, L.E., Gentil, P., Bemben, M.G., and Bottaro, M. 2015. Dissociated time course of muscle damage recovery between single- and multi-joint exercises in highly resistance-

trained men. J. Strength Cond. Res. 29(9): 2594-2599.

doi:10.1519/JSC.0000000000000899.

Swinton, P.A., Lloyd, R., Agouris, I., and Stewart, A. 2009. Contemporary training practices in 
elite british powerlifters: Survey results from an international competition. J. Strength Cond. Res. 23(2): 380-384. doi:10.1519/JSC.0b013e31819424bd.

Tug, S., Mehdorn, M., Helmig, S., Breitbach, S., Ehlert, T., and Simon, P. 2016. Exploring the Potential of cfDNA Measurements After an Exhaustive Cycle Ergometer Test as a Marker for Performance Related Parameters. Int. J. Sports Physiol. Perform. 12(9). doi:10.1123/ijspp.2016-0157.

Velders, M., Treff, G., Machus, K., Bosnyák, E., Steinacker, J., and Schumann, U. 2014. Exercise is a potent stimulus for enhancing circulating DNase activity. Clin. Biochem. 47(6): 471-474. doi:10.1016/j.clinbiochem.2013.12.017.

Willy, R.W., Kyle, B.A., Moore, S.A., and Chleboun, G.S. 2001. Effect of cessation and resumption of static hamstring muscle stretching on joint range of motion. J. Orthop. Sport. Phys. Ther. 31(3): 138-144. doi:10.2519/jospt.2001.31.3.138.

Zainuddin, Z., Newton, M., Sacco, P., and Nosaka, K. 2005. Effects of massage on delayed-onset muscle soreness, swelling, and recovery of muscle function. J. Athl. Train. 40(3): 174. doi:10.1136/bjsm.37.1.72.

Zourdos, M.C., Henning, P.C., Jo, E., Khamoui, A. V., Lee, S.R., Park, Y.M., Naimo, M., Panton, L.B., Nosaka, K., and Kim, J.S. 2015. Repeated bout effect in muscle-specific exercise variations. J. Strength Cond. Res. 29(8): 2270-2276. doi:10.1519/JSC.0000000000000856.

Zourdos, M.C., Klemp, A., Dolan, C., Quiles, J.M., Schau, K.A., Jo, E., Helms, E., Esgro, B., Duncan, S., Garcia Merino, S., and Blanco, R. 2016. Novel resistance training-specific rating of perceived exertion scale measuring repetitions in reserve. J. Strength Cond. Res. 30(3): 784-791. doi:10.1519/JSC.0000000000001049. 
116 Table 1. Subject Characteristics

117

\begin{tabular}{ccccccccc}
\hline & $\begin{array}{c}\text { Age } \\
(\mathbf{y r s})\end{array}$ & $\begin{array}{c}\text { Height } \\
\mathbf{( c m )}\end{array}$ & $\begin{array}{c}\text { Body } \\
\text { mass (kg) }\end{array}$ & $\begin{array}{c}\text { Body fat } \\
\mathbf{( \% )}\end{array}$ & $\begin{array}{c}\text { TA } \\
\mathbf{( y r s )}\end{array}$ & $\begin{array}{c}\text { Squat } \\
\mathbf{1 R M}(\mathbf{k g})\end{array}$ & $\begin{array}{c}\text { Bench } \\
\text { press } \\
\mathbf{1 R M}(\mathbf{k g})\end{array}$ & $\begin{array}{c}\text { Deadlift } \\
\mathbf{1 R M}(\mathbf{k g})\end{array}$ \\
\hline $\begin{array}{c}\text { Mean } \pm \\
\text { SD }\end{array}$ & 24.5 & 173.43 & 84.01 & 11.29 & 7.1 & 159.00 & 127.60 & 178.30 \\
\hline
\end{tabular}

118 Training Age (TA). One-repetition Maximum (1RM). N=12.

119

120

121

122

123

124

125

126

127

128

129

130

131

132

133

134

135

136

137

138

139

140

141

142

143

144

145

146

147

148

149

150

151

152

153

154 
Table 2. Timeline of events

\begin{tabular}{|c|c|c|c|c|c|}
\hline & Day 1 (Mon.) & Day 2 (Tues.) & Day 3 (Wed.) & Day 4 (Thurs.) & Day 5 (Fri.) \\
\hline $\begin{array}{c}\text { Week } \\
1\end{array}$ & & & $\begin{array}{ll}\text { - } & \text { HHQ } \\
- & \text { PAQ } \\
\text { - } & \text { APT } \\
\text { - } & 1 \text { RM testing }\end{array}$ & & - LES \\
\hline $\begin{array}{c}\text { Week } \\
2\end{array}$ & $\begin{array}{ll}\text { - } & \text { MD collection } \\
\text { - } & \text { PF collection } \\
\text { - } & \text { DEB (SQ or } \\
& \text { DL) } \\
\text { - } & \text { PF collection } \\
\text { - } & \text { MD collection }\end{array}$ & $\begin{array}{ll}\text { - } & \text { MD } \\
& \text { collection } \\
\text { - } & \text { PF collection }\end{array}$ & $\begin{array}{l}\text { - } \quad \text { MD collection } \\
\text { - }\end{array}$ & $\begin{array}{ll}\text { - } & \text { MD collection } \\
\text { - } & \text { PF collection }\end{array}$ & $\begin{array}{ll}\text { - } & \text { MD collection } \\
\text { - } & \text { PF collection } \\
\text { - } & \text { LES }\end{array}$ \\
\hline $\begin{array}{c}\text { Week } \\
3\end{array}$ & $\begin{array}{ll}\text { - } & \text { MD collection } \\
\text { - } & \text { PF collection } \\
\text { - } & \text { DEB (BP) } \\
\text { - } & \text { PF collection } \\
\text { - } & \text { MD collection }\end{array}$ & $\begin{array}{ll}\text { - } & \text { MD } \\
& \text { collection } \\
\text { - } & \text { PF collection }\end{array}$ & $\begin{array}{l}\text { - } \quad \text { MD collection } \\
\text { - } \quad \text { PF collection }\end{array}$ & $\begin{array}{ll}\text { - } & \text { MD collection } \\
\text { - } & \text { PF collection }\end{array}$ & $\begin{array}{ll}\text { - } & \text { MD collection } \\
\text { - } & \text { PF collection } \\
\text { - } & \text { LES }\end{array}$ \\
\hline $\begin{array}{c}\text { Week } \\
4\end{array}$ & $\begin{array}{ll}\text { - } & \text { MD collection } \\
\text { - } & \text { PF collection } \\
\text { - } & \text { DEB (SQ or } \\
& \text { DL) } \\
\text { - } & \text { PF collection } \\
\text { - } & \text { MD collection }\end{array}$ & $\begin{array}{ll}\text { - } & \text { MD } \\
\text { - collection } \\
\text { - } & \text { PF collection }\end{array}$ & $\begin{array}{ll}\text { - } & \text { MD collection } \\
\text { - } & \text { PF collection }\end{array}$ & $\begin{array}{ll}\text { - } & \text { MD collection } \\
\text { - } & \text { PF collection }\end{array}$ & $\begin{array}{ll}\text { - } & \text { MD collection } \\
\text { - } & \text { PF collection } \\
\text { - } & \text { LES }\end{array}$ \\
\hline
\end{tabular}


181 182

Table 3. Comparison of percentage change from pre-exercise to each time point in all conditions.

\begin{tabular}{|c|c|c|c|c|c|c|}
\hline & Lift & Post & $24 \mathrm{hr}$ & $48 \mathrm{hr}$ & $72 \mathrm{hr}$ & $96 \mathrm{hr}$ \\
\hline \multirow[t]{3}{*}{ S (\%) } & Squat & $0.49 \pm 1.14$ & $-0.25 \pm 1.07$ & $-0.04 \pm 0.79$ & $-0.73 \pm 1.15$ & $-0.82 \pm 0.67$ \\
\hline & $\begin{array}{l}\text { Bench } \\
\text { press }\end{array}$ & $2.32 \pm 1.36^{* \dagger}$ & $-0.27 \pm 1.36$ & $-0.41 \pm 1.43$ & $0.01 \pm 1.31$ & $0.11 \pm 1.71$ \\
\hline & Deadlift & $0.45 \pm 0.76$ & $-0.32 \pm 0.82$ & $-0.41 \pm 1.16$ & $-0.56 \pm 0.97$ & $-0.87 \pm 0.96$ \\
\hline \multirow[t]{5}{*}{$\begin{array}{c}\text { ROM } \\
(\%)\end{array}$} & $\begin{array}{c}\text { Squat } \\
\text { (H) }\end{array}$ & $-7.15 \pm 7.36$ & $-6.14 \pm 11.26$ & $-9.05 \pm 16.16^{*}$ & $-5.59 \pm 15.23$ & $-8.64 \pm 17.38$ \\
\hline & $\begin{array}{l}\text { Squat } \\
\text { (Q) }\end{array}$ & $9.66 \pm 10.11$ & $-3.28 \pm 28.17$ & $3.76 \pm 27.33$ & $4.01 \pm 19.38$ & $16.26 \pm 21.36$ \\
\hline & $\begin{array}{c}\text { Bench } \\
\text { press (E) }\end{array}$ & $-2.62 \pm 2.63$ & $-1.14 \pm 3.42$ & $-0.41 \pm 3.19$ & $-0.32 \pm 3.31$ & $-0.69 \pm 2.79^{\dagger}$ \\
\hline & $\begin{array}{c}\text { Deadlift } \\
\text { (H) }\end{array}$ & $-1.99 \pm 6.98$ & $-0.42 \pm 8.21$ & $-3.16 \pm 7.64$ & $-3.25 \pm 8.15$ & $-2.96 \pm 4.62$ \\
\hline & $\begin{array}{c}\text { Deadlift } \\
(\mathbf{Q})\end{array}$ & $-7.16 \pm 16.12^{\dagger}$ & $-2.12 \pm 17.19$ & $-2.78 \pm 18.95$ & $-0.67 \pm 16.37$ & $-2.94 \pm 13.83^{\dagger}$ \\
\hline \multirow[t]{5}{*}{$\begin{array}{c}\text { DOMS } \\
(\%)\end{array}$} & $\begin{array}{l}\text { Squat } \\
\text { (H) }\end{array}$ & $-2.96 \pm 14.17$ & $-26.73 \pm 15.38$ & $-17.89 \pm 22.86$ & $-12.67 \pm 16.72$ & $-10.35 \pm 11.65$ \\
\hline & $\begin{array}{l}\text { Squat } \\
\text { (Q) }\end{array}$ & $-3.71 \pm 12.26$ & $-17.99 \pm 11.66$ & $-20.13 \pm 14.04$ & $-11.91 \pm 20.17$ & $-4.87 \pm 16.07$ \\
\hline & $\begin{array}{c}\text { Bench } \\
\text { press }(C)\end{array}$ & $6.53 \pm 9.34$ & $-25.63 \pm 16.97$ & $-19.26 \pm 15.53$ & $-8.66 \pm 14.82$ & $-0.79 \pm 13.30$ \\
\hline & $\begin{array}{c}\text { Deadlift } \\
\text { (H) }\end{array}$ & $-1.08 \pm 35.86$ & $-16.51 \pm 19.27$ & $-10.56 \pm 27.27$ & $-9.46 \pm 21.35$ & $2.13 \pm 22.50$ \\
\hline & $\begin{array}{c}\text { Deadlift } \\
(\mathbf{Q})\end{array}$ & $-6.87 \pm 9.54$ & $-15.32 \pm 10.07$ & $-11.62 \pm 14.91$ & $-6.09 \pm 11.81$ & $-5.84 \pm 13.96$ \\
\hline \multirow{3}{*}{$\begin{array}{l}\text { LDH } \\
(\%)\end{array}$} & Squat & $16.38 \pm 14.37$ & $6.50 \pm 24.50$ & $2.54 \pm 12.43$ & $5.28 \pm 11.35^{*}$ & $6.90 \pm 19.18$ \\
\hline & $\begin{array}{l}\text { Bench } \\
\text { press }\end{array}$ & $4.05 \pm 9.73$ & $-1.11 \pm 17.87$ & $-6.45 \pm 13.17$ & $-10.21 \pm 9.43$ & $-2.86 \pm 14.19$ \\
\hline & Deadlift & $8.77 \pm 12.87$ & $-2.11 \pm 12.51$ & $-2.71 \pm 15.91$ & $-1.44 \pm 18.32$ & $-2.97 \pm 19.19$ \\
\hline \multirow[t]{3}{*}{ CK (\%) } & Squat & $66.99 \pm 55.53$ & $-15.38 \pm 48.96$ & $-9.97 \pm 33.50$ & $-15.03 \pm 34.72$ & $-30.15 \pm 25.71$ \\
\hline & $\begin{array}{l}\text { Bench } \\
\text { press }\end{array}$ & $39.42 \pm 43.80$ & $-8.87 \pm 56.44$ & $-21.79 \pm 30.39$ & $-24.69 \pm 29.17$ & $-13.69 \pm 43.93$ \\
\hline & Deadlift & $78.77 \pm 70.10$ & $-8.83 \pm 28.69$ & $-18.88 \pm 31.94$ & $-12.31 \pm 33.12$ & $-5.27 \pm 44.09$ \\
\hline \multirow{3}{*}{$\begin{array}{c}\text { cfDNA } \\
(\%)\end{array}$} & Squat & $5.33 \pm 5.79$ & $0.81 \pm 8.38$ & $4.27 \pm 7.29$ & $6.05 \pm 7.82^{*}$ & $7.44 \pm 9.78^{* \star}$ \\
\hline & $\begin{array}{l}\text { Bench } \\
\text { press }\end{array}$ & $3.48 \pm 4.47$ & $-0.28 \pm 5.49$ & $0.85 \pm 5.33$ & $-1.18 \pm 5.80$ & $1.73 \pm 5.01$ \\
\hline & Deadlift & $1.80 \pm 3.99$ & $-1.31 \pm 3.96$ & $-0.01 \pm 3.96$ & $1.86 \pm 5.61$ & $1.54 \pm 6.96$ \\
\hline \multirow{3}{*}{$\begin{array}{c}\mathrm{ACV} \\
(\%)\end{array}$} & Squat & $-9.85 \pm 11.56$ & $-9.13 \pm 7.98$ & $-11.39 \pm 12.28$ & $-8.61 \pm 7.98$ & $-4.75 \pm 9.29$ \\
\hline & $\begin{array}{l}\text { Bench } \\
\text { press }\end{array}$ & $-26.69 \pm 12.90^{\dagger}$ & $-5.83 \pm 11.14$ & $-5.85 \pm 12.35$ & $-2.93 \pm 12.22$ & $-3.67 \pm 12.04$ \\
\hline & Deadlift & $-6.99 \pm 18.85$ & $-5.72 \pm 14.63$ & $-6.39 \pm 14.43$ & $-6.06 \pm 15.38$ & $-4.05 \pm 13.71$ \\
\hline
\end{tabular}

183

184

185

186

187

188

189

190

191

192
Data are mean \pm SD. * significantly greater than bench press, $\uparrow$ significantly greater than squat, $₫$ significantly greater change than deadlift. Significance at $p<0.05$ are in bold. Swelling measurements were taken in the thigh for squat and deadlift and the upper arm for bench press. Swelling (S). Range of Motion (ROM). Hamstring (H). Quadriceps (Q). Elbow (E). Delayed Onset Muscle Soreness (DOMS). Lactate Dehydrogenase (LDH). Creatine Kinase (CK). Chest (C). Cell-free DNA (cfDNA). Average Concentric Velocity (ACV). 


\section{Figure captions}

194 Figure 1. Changes in limb swelling within exercise for the squat, bench press, and deadlift (A).

195 Limb swelling measurements were taken in the thigh for the squat and deadlift and upper arm in

196 bench press conditions. Changes in Performance Fatigue (ACV) within exercise for the squat,

197 bench press, and deadlift (B). Changes in joint ROM for the hamstring-elbow (C) and

198 quadriceps-elbow (D) within exercise for the squat, bench press, and deadlift. ROM

199 measurements were taken at the knee for the hamstring and quadriceps for the squat and deadlift

200 and at the elbow for the triceps for the bench press conditions. Changes in hamstring-chest (E)

201 and quadriceps-chest (F) pain-pressure threshold within exercise for the squat, bench press, and

202 deadlift. Pain-pressure threshold measurements were taken in the hamstring and quadriceps for

203 the squat and deadlift and in the chest the triceps for the bench press conditions. Decreases in

$204 \mathrm{kPa}$ denotes an increase in muscle soreness. Average Concentric Velocity (ACV). Range of

205 Motion (ROM). † Significant change from pre-exercise in the squat; *Significant change from

206 pre-exercise in the bench press. $¥$ Significant change from pre-exercise in the deadlift. Data are

207 mean \pm SD.

Figure 2. Changes in LDH (A), CK (B), and cfDNA (C) within exercise for the squat, bench press, and deadlift. Lactate Dehydrogenase (LDH). Creatine Kinase (CK). Cell-free DNA (cfDNA). *Significant change from pre-exercise in the squat; ${ }^{\$}$ Significant change from preexercise in the deadlift. Data are mean \pm SE.

Figure 3. Correlation between immediately percentage change from baseline post-exercise 

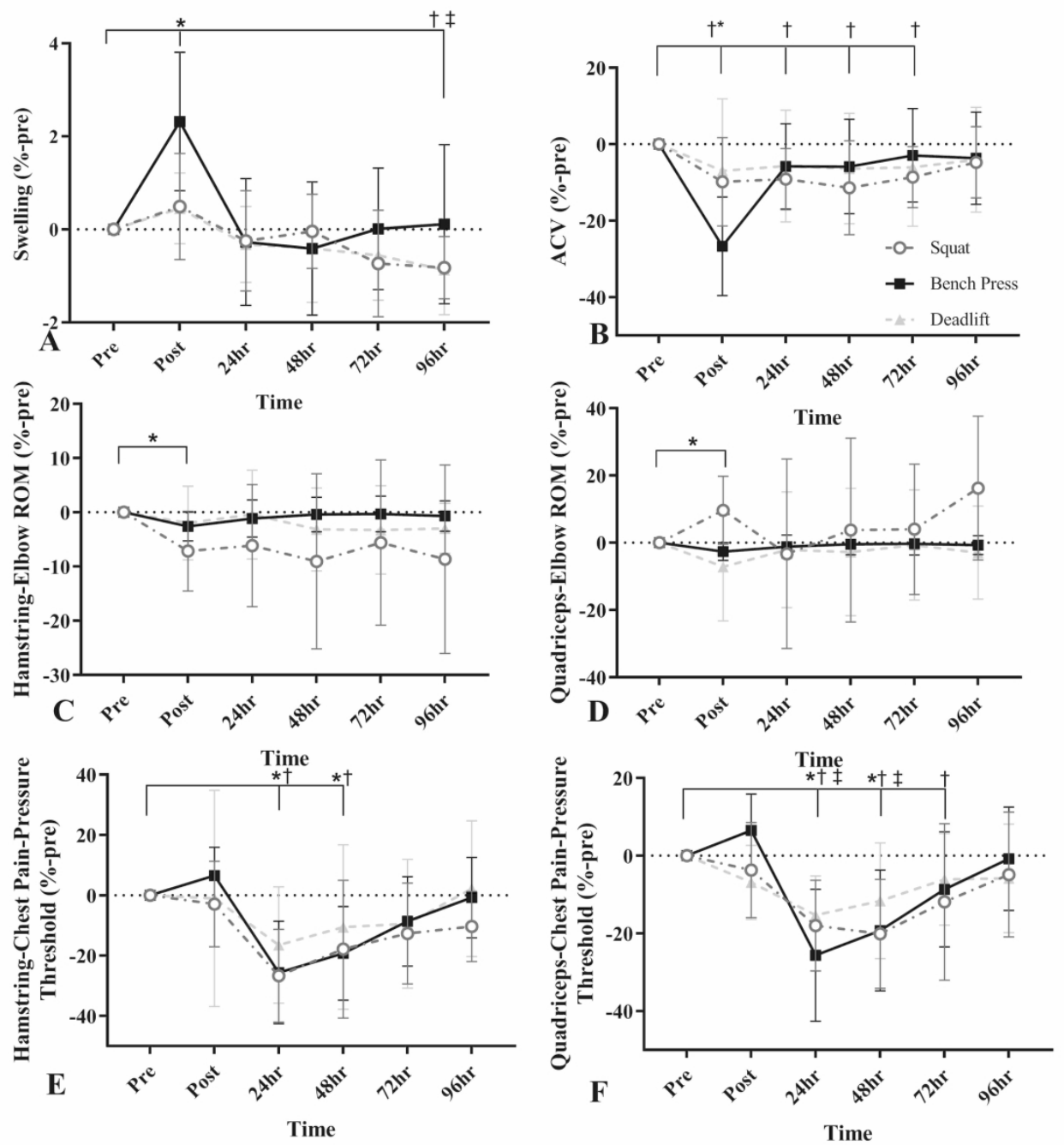

Changes in limb swelling within exercise for the squat, bench press, and deadlift (A). Limb swelling measurements were taken in the thigh for the squat and deadlift and upper arm in bench press conditions. Changes in Performance Fatigue (ACV) within exercise for the squat, bench press, and deadlift (B). Changes in joint ROM for the hamstring-elbow (C) and quadriceps-elbow (D) within exercise for the squat, bench press, and deadlift. ROM measurements were taken at the knee for the hamstring and quadriceps for the squat and deadlift and at the elbow for the triceps for the bench press conditions. Changes in hamstringchest (E) and quadriceps-chest (F) pain-pressure threshold within exercise for the squat, bench press, and deadlift. Pain-pressure threshold measurements were taken in the hamstring and quadriceps for the squat and deadlift and in the chest the triceps for the bench press conditions. Decreases in kPa denotes an increase in muscle soreness. Average Concentric Velocity (ACV). Range of Motion (ROM). +Significant change from pre-exercise in the squat; *Significant change from pre-exercise in the bench press. $\neq$ Significant change from pre-exercise in the deadlift. Data are mean \pm SD. 

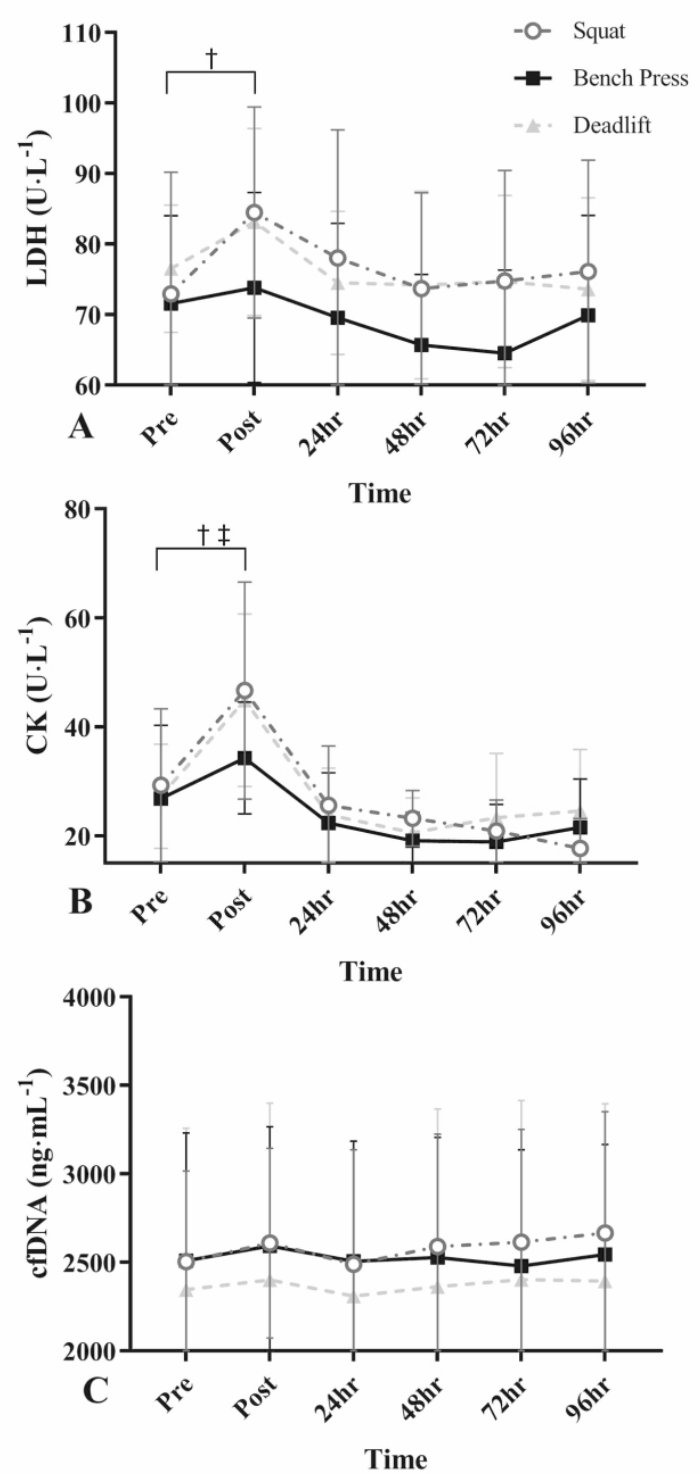

Changes in LDH (A), CK (B), and cfDNA (C) within exercise for the squat, bench press, and deadlift. Lactate Dehydrogenase (LDH). Creatine Kinase (CK). Cell-free DNA (cfDNA). *Significant change from pre-exercise in the squat; \$Significant change from pre-exercise in the deadlift. Data are mean \pm SE.

$114 \times 231 \mathrm{~mm}(300 \times 300 \mathrm{DPI})$ 

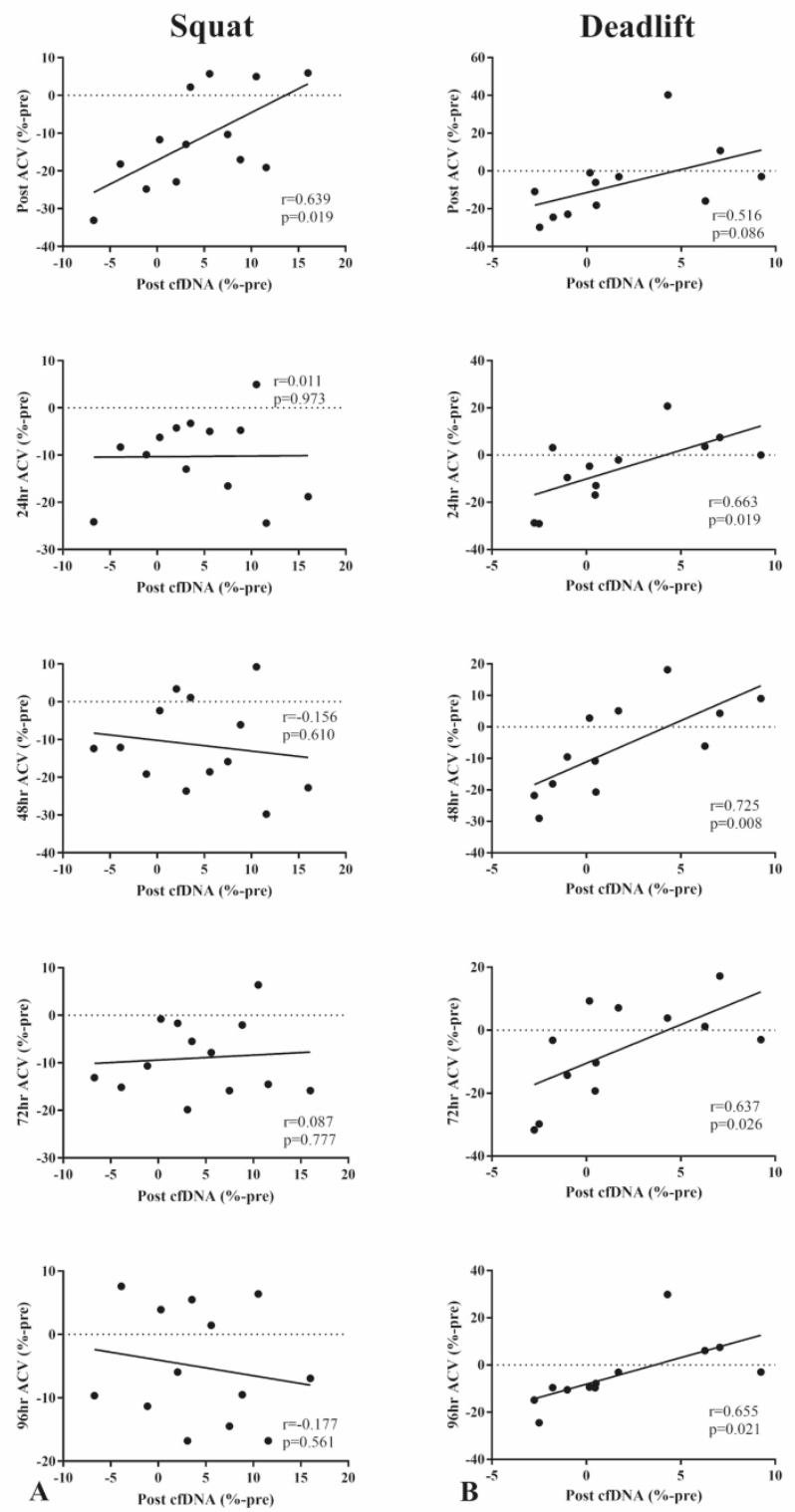

Correlation between immediately percentage change from baseline post-exercise cfDNA and all time points of percentage change ACV for squat (A) and deadlift (B). Cell-free DNA (cfDNA). Average Concentric Velocity $(\mathrm{ACV})$.

$145 \times 263 \mathrm{~mm}(300 \times 300 \mathrm{DPI})$ 